\title{
Immobilization of a Catalytically Active Rhodium Complex by Electrostatic Interactions of Multiply Charged Phosphine Ligands with a Soluble Polyelectrolyte and Recovery by Ultrafiltration
}

\author{
Ernst Schwab and Stefan Mecking*
}

Institut für Makromol ekulare Chemie und Freiburger Materialforschungszentrum der Albert-Ludwigs-Universität Freiburg, Stefan-Meier-Strasse 31, D-79104 Freiburg, Germany

\begin{abstract}
Summary: Binding via noncovalent ed ectrostatic interactions of multiply sulfonated phosphine ligands with a sol uble pol yel ectrol yte represents a convenient approach for immobilization of a catalytically active rhodium complex. As a polyelectrolyte, PDADMA-BArF ${ }_{4}$ (poly(diallyldimethylammonium tetrakis(3,5-bis(trifluoromethyl )phenyl)borate)) can be utilized. The pol yel ectroIytebound catalyst is activefor hexenehydroformylation, and it can be recovered and recycled by ultrafiltration.
\end{abstract}

Homogeneous catalysts based on soluble transitionmetal complexes ${ }^{1}$ display high activities and selectivities under mild conditions in a variety of reactions. The catalytic properties can be optimized and adjusted to different substrates by variations of the ligands, most often phosphines, coordinating to the metal center. These advantages of homogeneous catalysts are opposed by a usually tedious separation from the products after the reaction, a problem not encountered with typical heterogeneous catalysts. In hydroformylation, as the largest scale application of homogeneous transitionmetal catalysis, the separation of high-boiling side products (formed by condensation reactions) from the catalyst is often required. The development of systems combining the advantages of classical homogeneous and heterogeneous catalysts remains a challenge. Most approaches for immobilization of metal complexes have employed microporous organic or inorganic solids; however, these have met with limited success to date. ${ }^{2}$ By comparison, the success of aqueous two-phase catalysis is demonstrated by its large-scale industrial application in the hydroformylation of propene. ${ }^{3}$ However, aqueous two-phase catalysis requires a low yet sufficient water solubility of the substrates, strongly limiting its scope. As a different strategy, binding of metal complexes to colloidal structures (dimensions of $1-1000 \mathrm{~nm}$ ) is finding increasing attention. Soluble polymers, ${ }^{4,5}$ including dendrimers, ${ }^{6,7}$ have been utilized as supports. The

* To whom correspondence should be addressed. Fax: +49 761203 6319. E-mail: mecking@uni-freiburg.de.

(1) Applied Homogeneous Catalysis with Organometallic Compounds; Cornils, B., Herrmann, W. A., Eds.; Wiley-VCH: Weinheim, Germany, 1996.

(2) Reviews: (a) Pittman, C. U. In Comprehensive Organometallic Chemistry; Wilkinson, G., Stone, F. G. A., Abel, E. W., Eds.; Pergamon Press: Oxford, U.K., 1982; Vol. 8, pp 553-611. (b) Panster, P.; Wieland, S. In ref 1, pp 605-623. (c) Clark, J . H.; Kybett, A. P.; Macquarrie, D. J . Supported Reagents; VCH: Weinheim, Germany, 1992.

(3) Aqueous-Phase Organometallic Chemistry; Cornils, B., Herrmann, W. A., Eds.; Wiley-VCH: Weinheim, Germany, 1998. majority of these approaches have employed covalent attachment of ligands (e.g. of mono- or bidentate phosphines) to the polymer. As a different concept which has received relatively little attention to date, ${ }^{8}$ binding of the phosphine ligands of a catalytically active complex can also be achieved by electrostatic interactions ("ionic binding") with a soluble polyelectrolyte. Hereby, the drawbacks associated with the often tedious synthesis of polymers with covalently bound ligands are circumvented. At the same time, a variety of ligands with ionic substituents (most often sulfonate groups) developed for aqueous two-phase catalysis can be drawn upon. In

(4) (a) Manassen, J. Platinum Met. Rev. 1971, 15, 142-143. (b) Bayer, E.; Schurig, V. Angew. Chem. 1975, 87, 484-485; Angew. Chem., Int. Ed. Engl. 1975, 14, 493-494. (c) Bayer, E.; Schurig, V. CHEMTECH 1976, 212-214. (d) Bergbreiter, D. E.; Chandran, R. J . Org. Chem. 1986, 51, 4754-4760. (e) Bergbreiter, D. E. CHEMTECH 1987, 686690. (f) Bergbreiter, D. E.; Zhang, L.: Mariagnanam, V. M. J Am. Chem. Soc. 1993, 115, 9295-9296. (g) Malmström, T.; Weigl, H. Andersson, C. Organometallics 1995, 14, 2593-2596. (h) Han, H.; J anda, K. D. J . Am. Chem. Soc. 1996, 118, 7632-7633. (i) Kobayashi, S.; Nagayama, S. J. Am. Chem. Soc. 1996, 118, 8977-8978. (j) Bolm C.; Gerlach, A. Angew. Chem. 1997, 109, 773-775; Angew. Chem., Int. Ed. Engl. 1997, 36, 741-743. (k) Ajjou, A. N.; Alper, H. J . Am. Chem Soc. 1998, 120, 1466-1468.

(5) Recent review: Beller, M.; Krauter, J . G. E. In ref 3, pp 577581

(6) (a) Knapen, J . W. J .; van der Made, A. W.; de Wilde, J . C.; van Leeuwen, P. W. N. M. Wijkens, P.; Grove, D. M.; van Koten, G. Nature 1994, 372, 659-663. (b) Brunner, H. J . Organomet. Chem. 1995, 500 39-46. (c) Bhyrappa, P.; Young, J. K.; Moore, J. S.; Suslick, K. S. J Am. Chem. Soc. 1996, 118, 5708-5711. (d) Seebach, D.; Marti, R. E.; Hintermann, T. Helv. Chim. Acta 1996, 79, 1710-1740. (e) Reetz, M. T.; Lohmer, G.; Schwickardi, R. Angew. Chem., Int. Ed. Engl. 1997, 36, 1526-1529; Angew. Chem. 1997, 109, 1559-1562. (f) Chow, H.F.; Mak, C. C. J Org. Chem. 1997, 62, 5116-5127. (g) Koellner, C. Pugin, B.; Togni, A. J. Am. Chem. Soc. 1998, 120, 10274-10275. (h) Hovestad, N. J .; Eggeling, E. B.; Heidbuechel, H.J .; J astrzebski, J . T. B. H.; Kragl, U.; Keim, W.; Vogt, D.; van Koten, G. Angew. Chem. Int. Ed. 1999, 38, 1655-1658; Angew. Chem. 1999, 111, 1763-1765. (i) Brinkmann, N.; Giebel, D.; Lohmer, G.; Reetz, M. T.; Kragl, U. J . Catal. 1999, 183, 163-168. (j) Oosterom, G. E.; van Haaren, R. J .; Reek, J. N. H.; Kamer, P. C. J .; van Leeuwen, P. W. N. M. Chem. Commun. 1999, 1119-1120. (k) Albrecht, M.; Hovestad, N. J .; Boersma, J .; van Koten, G. Chem. Eur. J . 2001, 7, 1289-1294.

(7) Recent related reviews on dendrimers: (a) Fischer, M.; Vögtle, F. Angew. Chem., Int. Ed. 1999, 38, 885-905; Angew. Chem. 1999, 111, 934-955. (b) Bosman, A. W.; J anssen, H. M.; Meijer, E. W. Chem. Rev. 1999, 99, 1665-1688. (c) Hecht, S.; Fréchet, J. M. J. Angew. Chem., Int. Ed. 2001, 40, 74-91; Angew. Chem. 2001, 113, 76-94. (d) Oosterom, G. E.; Reek, J . N. H.; Kamer, P. C. J .; van Leeuwen, P. W. N. M. Angew. Chem., Int. Ed. 2001, 40, 1828-1849; Angew. Chem. 2001, 113, 1878-1901.

(8) (a) For example, for a brief mention of binding of a phosphine ligand substituted with a single $\mathrm{HNR}_{3}{ }^{+}$moiety, of.: Bergbreiter, D. E.; Case, B. L.; Liu, Y.-S.; Caraway, J. W. Macromol ecules 1998, 31 6053-6062. Immobilization on ion-exchange resins: (b) Tang, S. C.; Paxson, T. E.; Kim, L. J . Mol. Catal. 1980, 9, 313-321. (c) Smith, R. T.; Ungar, R. K.; Baird, M. C. Transition Met. Chem. 1982, 7, 288289. (d) Toth, I.; Hanson, B. E.; Guo, I.; Davis, M. E. Catal. Lett. 1991 $8,209-214$. 
Scheme 1. Preparation of PDADMA-BArF ${ }_{4}$ and Binding of the Rhodium Complex

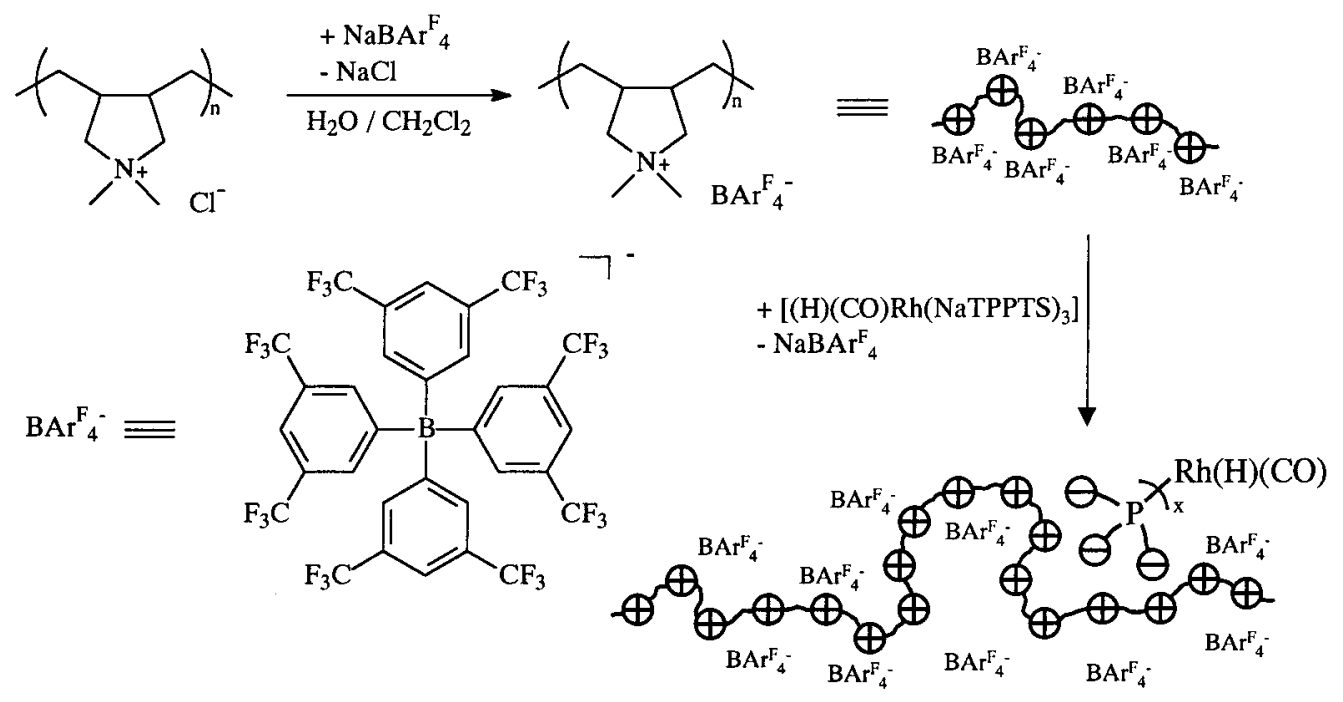

addition, by comparison to covalent attachment, ionic binding of ligands to the polymer offers the advantage of a strong yet reversible interaction with the polymer. Consequently, the spatial array of the polymer-bound ligands could be expected to adjust more freely to the steric requirements for coordination at the metal center instead of being dictated by the polymer. We now report a simple method for immobilization employing el ectrostatic interactions of multiply sulfonated phosphine ligands with a soluble polyelectrolyte and separation and recycling of a corresponding rhodium-based hydroformylation catalyst by ultrafiltration. ${ }^{9}$

As a source for a suitable cationic polyelectrolyte, commercially available poly(diallyldimethylammonium chloride) (PDADMAC) was employed. For catalysis the presence of inert counterions instead of chloride is desirable. In addition, large organic counterions can increase solubility of the polyelectrolyte in organic solvents. Reaction of PDADMAC with 1 equiv of $\mathrm{Na}$ $\mathrm{BAr}_{4}{ }^{10}$ resulted in formation of PDADMA-BArF ${ }_{4}$ : utilizing a two-phase mixture of water and methylene chloride, the product precipitates selectively (Scheme 1). Washing twice with water yielded the counterionexchanged polyelectrolyte free of chloride ${ }^{11}$ in high yield (90\%). As anticipated, the material possesses a high solubility in polar organic solvents, such as methanol and acetone. ${ }^{12}$ The high-molecular-weight PDADMAC utilized as a starting compound contains low-molecularweight fractions due to its broad molecular weight distribution. The latter were removed by ultrafiltration (vide infra) of the ion-exchanged polyelectrolyte. Utilizing PDADMA-BArF ${ }_{4}$ based on a polycation with $\mathrm{M}_{\mathrm{w}}=$ $3 \times 10^{5} \mathrm{~g} \mathrm{~mol}^{-1}$, ca. $5 \%$ of undesired low-molecularweight material passed the membrane. ${ }^{13}$ For efficient binding of a ligand to the soluble polyelectrolyte by (partial) exchange for the anionic counterions, multiple substitution of the ligand with ionic moieties is advan-

(9) Recent review on recovery of catalysts by ultrafiltration: Kragl, U.; Dreisbach, C.; Wandrey, Ch. In ref 1, pp 832-843.

(10) (a) Brookhart, M.; Grant, B.; Volpe, A. F., J r. Organometallics 1992, 11, 3920-3922. (b) Nishida, H.; Takada, N.; Y oshimura, M.; Sonoda, T.; Kobayashi, H. Bull. Chem. Soc. J pn. 1984, 57, 2600-2604.

(11) Anal. Calcd for $\mathrm{C}_{40} \mathrm{H}_{28} \mathrm{BF}_{24} \mathrm{~N}$ : C, 48.55; $\mathrm{H}, 2.85 ; \mathrm{N}, 1.41$. Found: $\mathrm{C}, 48.03 ; \mathrm{H}, 3.10 ; \mathrm{N}, 1.34 ; \mathrm{Cl}$ below detection limit (0.03\%).

(12) For example, the solubility of PDADMA-BArF ${ }_{4}$ in acetone exceeds $300 \mathrm{~g} \mathrm{~L}^{-1}$, whereas PDADMAC is virtually insoluble. tageous. Among a variety of ligands, this prerequisite is also fulfillled by the archetypical NaTPPTS ${ }^{14}$ (NaTPPTS $=$ tris(sodium-m-sulfonatophenyl)phosphane)<smiles>NS(=O)(=O)c1cccc(P(c2cccc(S(N)(=O)=O)c2)c2cccc(S(=O)(=O)O[Na])c2)c1</smiles>

NaTPPTS

containing three sulfonate substituents per molecule. Stirring the well-known $\left[(\mathrm{H}) \mathrm{Rh}(\mathrm{CO})(\mathrm{NaTPPTS})_{3}\right]^{15}$ with a methanol solution of PDADMA-BArF ${ }_{4}$ resulted in gradual dissolution of the rhodium complex (Scheme 1). ${ }^{16}$ Typically a $4: 1$ to $10: 1$ ratio of tetraal kylammonium to sulfonate groups was utilized, such that only a part of the $\mathrm{BAr}_{4}$ counterions was exchanged in order to maintain solubility of the polymer (a 1:1 adduct of the PDADMA polycation with TPPTS is completely insoluble in methanol ${ }^{17}$ ).

The electrostatically polymer bound complex was employed for hydroformylation of hexene. Typically 160 TO $\mathrm{h}^{-1}$ were observed at $80{ }^{\circ} \mathrm{C}$ and $30 \mathrm{bar}$ of $\mathrm{CO} / \mathrm{H}_{2} \cdot{ }^{18}$ Similar activities are observed in comparative experiments with the nonimmobilized complex, which con-

(13) (a) The average molecular weight of the PDADMAC used as a starting compound was according to the supplier (Aldrich). The meaningful molecular weight determination of polyelectrolytes is far from a routine procedure; for analysis of PDADMAC, cf.: Dautzenberg, H.; Goernitz, E.; J aeger, W. Macromol. Chem. Phys. 1998, 199, 15611571 and references cited therein. (b) A membrane of nominal $50 \mathrm{kDa}$ MWCO was utilized.

(14) (a) Kuntz, E. G. CHEMTECH 1987, 17, 570. (b) Kuntz, E. G. (Rhone-Poulenc), French Patent FR 2314910, 1975.

(15) (a) Herrmann, W. A.; Kulpe, J . A.; Konkol, W.; Bahrmann, H. J . Organomet. Chem. 1990, 389, 85-101. (b) Arhancet, J. P.; Davis M. E.; Merola, J . S.; Hanson, B. E. J . Catal. 1990, 121, 327-339.

(16) For the exchange of the sodium counterions of NaTPPTS for low-molecular-weight mono- or difunctional alkylammonium ions and utilization for hydroformylation, cf.: Bahrmann $\mathrm{H}$. In ref 1 , pp 644654.

(17) AAS analysis revealed less than $1 \%$ of the Rh employed to be present in the methanol supernatant of a 1:1 mixture (regarding ionic substituents) of PDADMA-BArF ${ }_{4}$ or PDADMAC with $[(\mathrm{H}) \mathrm{Rh}(\mathrm{CO})$ $(\mathrm{NaTPPTS})_{3}$. 
firms the unhindered accessibility of the polymer-bound rhodium centers. After a hydroformylation run, the reaction solution was subjected to ultrafiltration ${ }^{19}$ on an asymmetric polyethersulfone membrane (nominal MWCO $50 \mathrm{kDa}$ ). ${ }^{20}$ While the hydroformylation products and residual hexene rapidly passed the membrane, the polyelectrolyte-bound catalyst was fully retained. AAS of the retentate and fil trate demonstrated $98 \%$ rhodium recovery. This recovery corresponds to a retention of $99.8 \%$ per cell volume (the 10-fold amount of solvent with respect to the cell volume was pumped through the cell in these experiments). By comparison, the nonimmobilized complex passes the membrane under the same conditions; $>90 \%$ was found in the filtrate. When the catalyst solution was recycled, virtually the same catalytic activity was observed again (165 TO $\mathrm{h}^{-1}$ ). Subsequent ultrafiltration again afforded 93\% recovery of rhodium. The catalytic activities and rhodium losses upon recycling were found to be reproducible in inde-

(18) Typical reaction conditions: $16 \mu \mathrm{mol}$ of $\mathrm{Rh} ; 90 \mathrm{~mL}$ of methanol; $10 \mathrm{~mL}$ of hexene-1; 30 bar of $\mathrm{CO} / \mathrm{H}_{2}(1: 1) ; 3 \mathrm{~h} ; 80^{\circ} \mathrm{C}$. The $\mathrm{n} / \mathrm{i}$ ratio was 2.5 to 3.1. In methanol, the aldehyde products largely react to give acetals, which can be converted to the aldehydes again.

(19) UItrafiltrations were performed in a custom-made magnetically stirred stainless steel cell operated at a transmembrane pressure of $10 \mathrm{bar}$. The solution was pumped into the cell, and it was then filtered by pumping neat solvent through the cell (typically 10 cell volumes).

(20) PES membranes were supplied by Sartorius. Please note that the molecular weight cut off (MWCO) given by the supplier refers to water and also depends on the solute. Therefore, nominal MWCOs should be regarded only as a rough indication of the order of magnitude. pendent repetitive experiments. The $2-7 \%$ loss of rhodium present in the filtrate of each run presumably results from a partial oxidation of the phosphineligand. The batch experiments performed require excessive handling of catalyst sol utions, and some exposure to air cannot be excluded. However, this is not an intrinsic problem, since in potential applications a continuous closed system or an integrated membrane reactor would be used. An increase of flow rates during ultrafiltration of the cationic polyelectrolyte and higher catalyst loading are desirable. We are currently investigating other polyel ectrolytes and ligands.

In summary, in the system investigated binding of a metal complex to a polyelectrolyte via electrostatic interactions of multiply charged phosphine ligands with the polymer provides a convenient access to a polymerbound soluble catalyst. This soluble catalyst can be recovered and recycled effectively by means of ultrafiltration.

Acknowledgment. Funding by the Deutsche Forschungsgemeinschaft (Project Me1388) is gratefully acknowl edged. A generous loan of rhodium chloride was provided by degussa AG. We thank A. Rossel for construction of ultrafiltration cells. AAS analyses were carried out by S. Hirth-Walter. We are indebted to the Eugen-Graetz-Foundation and the Fonds der chemischen Industrie for financial support. 